\title{
Design of an Experiential Learning Course in Sensors, Measurement and Instrumentation
}

\author{
Vincent Chan*, Ahmad Ghasempoor, Devin Ostrom \\ Department of Mechanical and Industrial Engineering \\ Ryerson University \\ *v7chan@ryerson.ca
}

\begin{abstract}
Recently a new course in Sensors and Measurement was introduced to the Mechatronics Option in the Mechanical Engineering Program at Ryerson University. In order to enhance the learning and comprehension of fundamental concepts in measurement and instrumentation, experiential learning was introduced through the extensive use of "hands-on" laboratories to demonstrate the theory taught in the lectures. In the course, the application of modern instrumentation and measurement of both static and dynamic mechanical systems are covered through the use of interfacing of hardware sensors with Labview software. Students learn about transducers, signal conditioning, and analogue to digital data conversion through the writing of their own Labview programs which is used to collect and perform preliminary analysis of the data. These labs are designed to follow Kolb's experiential learning cycle, where students learn the theory, are introduced to the physical equipment, plan how they are going to program the Labview software to collect the data that they require, and then test their programs in the laboratory. Finally, after the lab, students are required to analyse the data they collected and write a lab report. By taking this experiential approach to learning, the course was successful in teaching and reinforcing the required principles to students.
\end{abstract}

Keywords: experiential learning, mechatronics, openended labs

\section{INTRODUCTION}

Since the introduction of a mechatronics option in to the $3^{\text {rd }}$ year curriculum of the mechanical engineering program at Ryerson University, the challenge for teaching faculty has been to ensure that mechanical engineering students comprehend and understand the electrical engineering concepts. Traditionally, theory presented to students in lectures was reinforced through the use of regimented and closely controlled laboratories. Recently, a new course was developed for the mechatronics option called, Measurement, Instrumentation and Sensors. This course was developed after consultation with our industry advisory committee. To help students understand the concepts in the course, the labs were designed to be centered on active experience and experiential learning. This was achieved through the use of Labview software, where students had to design both the user interface and how various sensors were read and interpreted by the system.

It was observed that some of the deficiencies of many engineering labs were: students were required to solve problems that they have not encountered, students were constrained to a short time period and students were usually taught with one single demonstration due to the logistics of large classes and economics.

The goal of the course was to teach students the application of modern instrumentation in experimental measurements of mechanical and thermal systems. Fundamentally, the concepts of static and dynamic measurements were reviewed. Various sensors such as transducers, thermocouples and strain gauges were investigated. Processes and methods that include signal conditioning, data transmission, and digital data acquisition systems were also taught and practiced in the labs.

\section{LITERATURE REVIEW}

Mechatronics can be defined as the combination of mechanical engineering, electronic control and systems design of a product or process. Due to its multidisciplinary nature, experiential learning in the laboratory can be very beneficial in helping the student comprehend and understand the concepts that are being taught. Experiential learning is the direct encounter with the concepts being investigated, rather than studying the theory in a textbook. Engineering is an applied science that requires hands-on skills that involves design, problem solving and analysis [1]. Much of a child's learning before school is experientially based. The same can also be said, as a young engineer's learning after formal education is much derived from experiential learning. 
Experiential learning is neither a new method of teaching nor is it a terminology for "hands-on learning". In 1976, L. Harrisberger et. al. and the ASEE undertook a study of six different experiential learning programs in engineering, with the oldest of the studied programs operating for over seventy years [2]. The programs ranged from only having a senior project with experiential learning to a program where the whole program contains experiential elements. The report noted, the experiential learning develop a set of outcomes that are not generally achieved in traditional courses. But it also found that there are some learning skills that are better achieved through traditional courses, such as engineering fundamentals.

At Loughborough University, a process control laboratory was designed to use Kolb's experiential learning cycle to enhance the student's understanding of process control [3]. Students were given an introductory lecture to the lab, including a telepresence simulation, in addition to lectures on the theory material covered in the lab. Pre-lab test questions and a preparatory session with a virtual laboratory were given to help students contextualize the labs objectives and to give them concrete experience. Finally, two lab sessions with the process control instrumentation were given to the students to allow enough time for the students to experiment. Post-lab test questions were given, as a chance for students to reflect over their experiences.

An experiential multidisciplinary design program was developed at the University of Michigan to help engineering students stretch beyond their comfort zones [4]. The goal of the program was to prepare students for a multidisciplinary world. Students would be given the opportunity to address professional practice, provide a high quality experiential opportunity and deepen the understanding of classroom acquired knowledge. The program at Michigan has four required elements: an introductory design, build and test project, a course that is to be taken outside of their major's department, a major multi-term, multidisciplinary design, build and test project and a mentorship/leadership requirement. Outcomes of the students include, the ability to recognize and define a problem, ability to identify, understand and solve an illdefined problem, strong quantitative and qualitative problem solving, a mindset and skills for continued learning and the drive and capability to bring solutions into production.

Game playing though a simulation is used at Purdue University to provide experiential learning in lean manufacturing concepts [5]. The author contends that instructional games and simulations by their virtue are experiential. In this game, "Lemonade Tycoon" students set up a virtual lemonade stand in a computer simulation game. They must select the location of the stand; choose a recipe for the lemonade, purchase supplies and set prices. The goal of the exercise was for students to apply lean manufacturing concepts each time they played the game, such as push, pull, kanban, bottleneck, cycle time, idle time, line balance and to illustrate worker behavior. At the end of each game, students were required to assess the effect of the lean improvement that they had applied and to plan which concept or concepts to apply in the next game. The author concluded that game playing allowed students to participate in activities that were too costly, dangerous or impractical to implement in the classroom. As well, it also encouraged collaboration and meaningful post game discussion. However, it was noted, that games and simulations require a large amount of time compared to traditional lectures and that they do not necessarily develop all competencies.

A machine shop class was integrated into the curriculum to provide experiential learning for other fundamental engineering courses at the University of San Diego [6]. A wooden model and acoustic guitar was made by students in support of a concurrent dynamics course. Sheet metal reinforcement of a hollow beam by the students was used to provide an experiential basis for beam theory in a mechanics of materials course. The kinematic analysis of a student machined compressed air reciprocating engine, which students assembled and tested worked well with lectures in machine design, dynamics and graphical communications. Finally, students were required to build and test a catapult in order to apply Taguchi design-of-experiment principles. In student and instructor outcomes surveys, the authors found that the experiential learning greatly enhanced the development of student's design and industrial abilities, and satisfaction and enthusiasm for the course.

\section{KOLB'S EXPERIENTIAL LEARNING CYCLE}

Kolb suggested that experiential learning was in fact a learning cycle made of four elements [7-8]. Advantageous learning occurs when students have a balance of these four elements during their learning experience. The elements are: (1) Concrete Experience, (2) Reflective Observations, (3) Abstract Conceptualization and (4) Active Experimentation. After gaining concrete experience, students should reflect on the observations. From which, the students could conceptualize their experiences and change outcomes of experimentations. This cycle is known as Kolb's experiential learning cycle and is shown in Figure 1 below. 


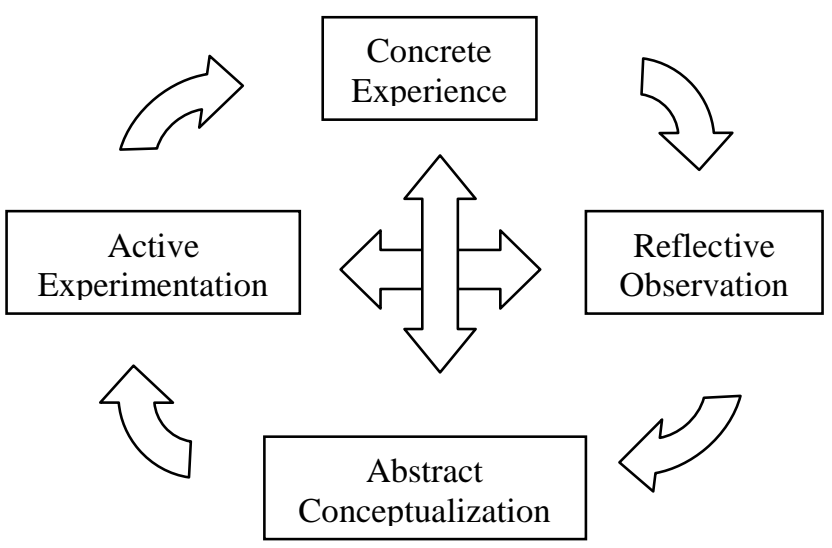

Fig. 1. Kolb's Experiential Learning Model

The vertical arrow represents the knowledge grasping dimension whereas the horizontal arrow represents the knowledge transformation dimension. Kolb's model distinguishes the independent modes of knowledge grasping to that of knowledge transformation.

During labs, students should be encouraged to perform the "active experimentation." However, this assumes that the students have already grasped the knowledge (concrete experience and abstract conceptualization) and have had time to have reflective observation in order to transform the knowledge during the active experimentation element. Unfortunately, too many laboratory sessions, students are simply following a list of instructions in a lab manual. This results in poor learning outcomes even though students have spent countless hours going through many different laboratory experiments.

\section{DESIGN OF LABORATORY EXPERIMENTS}

The laboratories provide support for the theory that is provided in class. Each of the labs, although measure different phenomenon, build on the experience of the students as they progress through the semester. The labs allow students to experiment with different sensors using Labview2010 data acquisition software with a NI PCIe6321 data acquisition board connected to a NI SCB-68 breakout board to allow easy connection of sensor leads. A photo of the general setup is seen in Fig. 2. Working in teams of two, they are introduced to the physical equipment, plan how they are going to collect the data, and then test their programs in the laboratory. A formal lab report is expected after each lab, so that students can reflect and conceptualize the lessons learned.

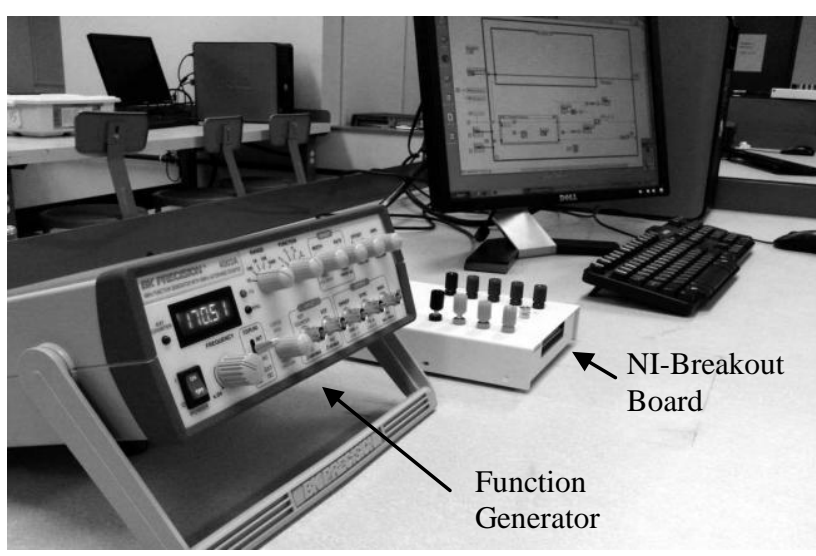

Fig. 2. General Experimental Setup

\subsection{Frequency Domain Representation of Signals}

For this first lab, students get the feel of how to "program" Labview by creating a very simple data acquisition algorithm. The general setup is shown in Fig. 2. The students use a benchtop function generator to feed a sine waveform into the ADC of the data acquisition board. The students are then required to build a program to read in the waveform and display the waveform on their computer screens, including the RMS of the signal and a spectrum. Mostly, the students are told step by step which blocks to add to their program. Students then test the effect of changing the number of samples and the sample rate on a number of different waveforms fed from the function generator, at a variety of frequencies. A formal lab report is required to be handed in, forcing the students to reflect on what they have learned.

\subsection{Strain Gauge Measurement Lab}

In this lab, a pair of strain gauges are mounted on a cantilevered beam. The dimensions of the beam are known as are a set of laboratory weights. The experimental setup is shown in Fig. 3.

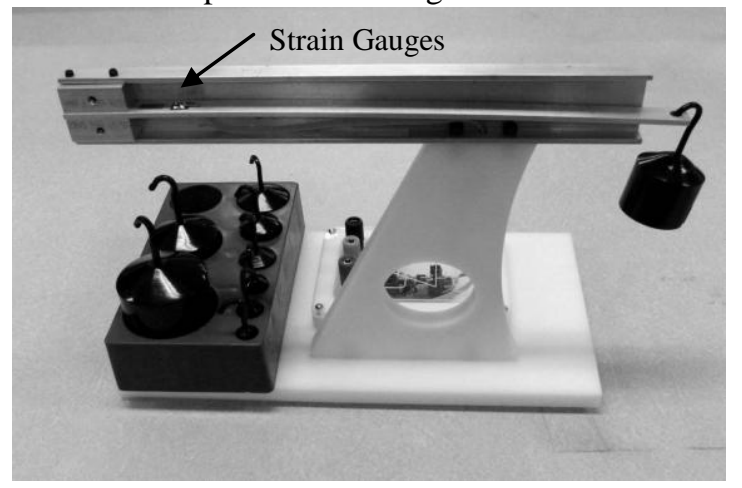

Fig. 3. Strain Gauge Experiment 
In this lab, students are expected to program their own block diagram in Labview, using the experiences that they gained in the first lab. As this lab has many similarities, students can conceptualize the concepts they have learned in the first lab to formulate both the block diagram and their front panel (GUI). Through a series of questions, students are given a hint on the types of properties that they are expected to measure, such as $\max , \min \mathrm{mV}$, frequency, etc. Although the first lab was very straight forward, in this lab, students are expected to determine the natural frequency of the beam, given the series of calibrated weights. At the end of the lab, students can then use their program and the strain gauge beam to measure weights of unknown values.

\subsection{Thermocouple Measurements Lab}

Students are taught the theory behind the Seebeck effect and the use of thermocouples in addition to digital signal filtering methods. The NI SCB-68 provides a coldjunction compensation. As part of the lab, students are provided with a K-type thermocouple, two small "Thermos" type containers, one for hot water and one for ice water and a thermometer, as seen in Fig. 4.

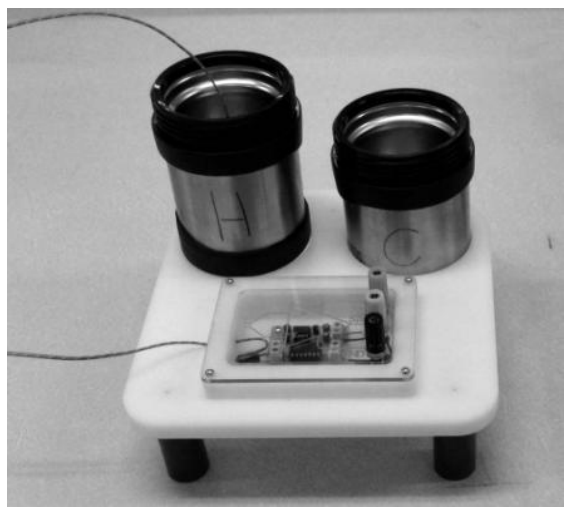

Fig. 4. Thermocouple Experiment

As in the strain gauge lab, students are expected to draw upon their previous experiments to program the block diagram and front panel in Labview. They are then expected to calibrate their system using the hot water and ice water baths. To clean the temperature readings over time, students are asked to experiment by adding digital filters, such as using an IIR or FIR filter in the program.

\subsection{Pressure Sensor Lab}

For this last lab, students are required to control the pressure in a small tank through the use of two solenoid controlled valves. One valve is on the inlet, at 100psi, and one valve is on the outlet that vents to atmosphere. A pressure transducer is located on a tap leading out of the small tank. The experimental setup is shown in Fig. 5.

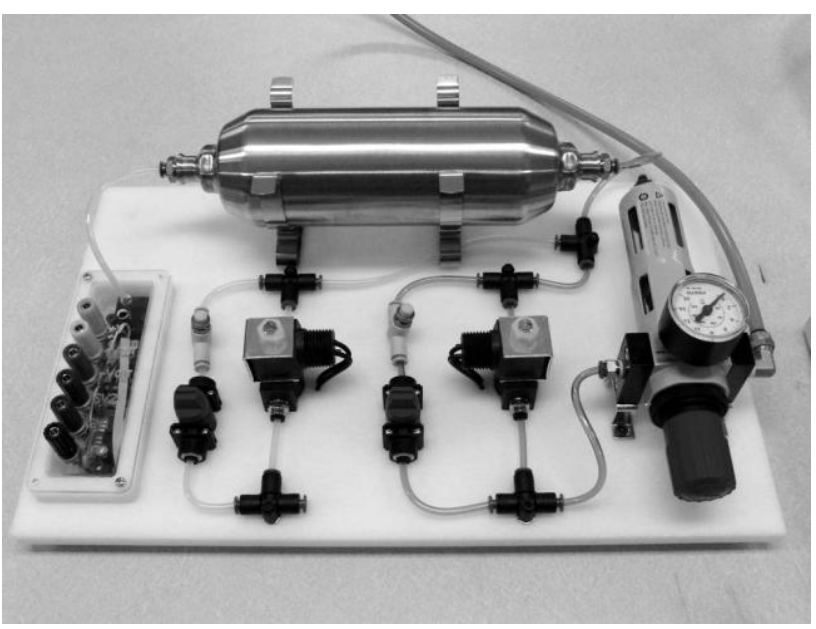

Fig. 5. Pressure Transducer Experiment

The goal of this lab was to write a program to control the pressure in the tank for any value that can be dialed in on the GUI. Additional marks were given to how fast the system would reach steady state, and how constant the pressure would remain at the set value. Inherently, the system's time response is slow, which added complexity to the control system. It was left to the students discretion as to which type of control system to implement (eg. P vs a full PID) and in fact some students experimented with many different types.

\section{CONCLUSIONS AND FUTURE WORK}

Students who enrol in the MEC751 Sensors course report that it is more work and more demanding than other typical courses, as the labs built on skills that they learned in previous labs but required them to use knowledge from previous courses, such as vibrations, controls, thermodynamics and dynamics. However, students were also clearly more satisfied with the course work, citing the large hands-on component of the labs, in addition to the skills learned in the labs in setting up and programming the experiments. In fact, one student commented that he wished there was the opportunity to design his own circuit and measurement system.

It should be also mentioned, that this large lab component of the course required additional work to both setup and run by faculty, lab technicians and teaching assistants. Also, the cost of the software license, sensors and data acquisition systems is quite considerable.

It can be concluded that this experiential learning method has helped students gain skills and confidence in working with both sensors and programming the software. Although each of the four labs involved different sensors and goals, the labs shared more in common than 
differences. This allowed students to progress through the steps with concrete experiences, reflective observations, abstract conceptualization and active experimentation with each new lab throughout the term.

Future work would include the creation of one or two additional labs. Also, the addition of a design project, where students would have to specify, purchase and construct a multi-sensor is also envisioned.

\section{Acknowledgements}

The authors would like to express their gratitude to the Department of Mechanical and Industrial Engineering for support and resources in building the equipment for this lab.

\section{References}

[1] Anonymous, Educating the Engineer of 2020: Adapting Engineering Education to the New Century. Washington, DC: National Academies Press, 2005, 192p.

[2] L. Harrisberger and American Society for Engineering Education,Washington, DC, "Experiential learning in engineering education," American Society for Engineering Education, One Dupont Circle, Suite 400, Washington, D, 1976.
[3] M. Abdulwahed and Z.K. Nagy, "Applying Kolb's experiential learning cycle for laboratory education," Journal of Engineering Education, 98(3), 2009, pp 283-294.

[4] A. J. Conger, B. Gilchrist, J. P. Holloway, A. Huang-Saad, V. Sick and T. H. Zurbuchen, "Experiential learning programs for the future of engineering education," in Transforming Engineering Education: Creating Interdisciplinary Skills for Complex Global Environments, 2010 IEEE (Dublin, Ireland), 2010, pp. 1-14.

[5] L. B. Ncube, "Exploring the application of experiential learning in developing technology and engineering concepts: The lean lemonade tycoon ${ }^{\mathrm{TM}}$," in Frontiers in Education Conference - Global Engineering: Knowledge without Borders, Opportunities without Passports, 2007. FIE '07. 37th Annual (Milwaukee, Wisconsin ), 2007, pp. F1J-5-F1J10.

[6] D.M. Malicky, J.G. Kohl, and M.Z. Huang, Integrating a machine shop class into the mechanical engineering curriculum: Experiential and inductive learning. International Journal of Mechanical Engineering Education, 38(2), 2010, pp135-146.

[7] D. A. Kolb, Experiential Learning: Experience as the Source of Learning and Development. Englewood Cliffs, N.J.: Prentice-Hall, 1984, 254p.

[8] M. Silberman, ed., The Handbook of Experiential Learning. San Francisco: Pfeiffer, 2007, 386p. 